\title{
EQUALITY OF OPPORTUNITY BETWEEN MEN AND WOMEN ON THE LABOUR MARKET - THE GENDER PAY GAP WITHIN THE EU MEMBER STATES
}

\author{
Oana Ancuța Stângaciu \\ "Vasile Alecsandri” University of Bacău \\ anca_stangaciu@yahoo.com
}

\begin{abstract}
The actions taken for the promotion of the equality of opportunity between men and women and for eliminating the direct or the indirect discrimination apply to the field of employment as well as to the field of education, health, culture, information and the participation in the decision making process. Starting from one of the objectives of the Strategy for the equality of opportunity, being aware of the real situation of women participation compared to men participation to the economical and social life, this analysis offers a perspective on the equality of opportunity between men and women in the field of employment, seen based on the statistical data. Thus, in order to quantify this phenomenon using methods specific to the statistical analysis, we used the gender pay gap indicator pertaining to the EU member states per total economy, as well as per economical activities, and the research results show that on the EU level there are still significant gender pay gaps.
\end{abstract}

\section{Keywords}

gender pay gap; earnings; NACE Rev.2. - Statistical Classification of Economic Activity

\section{JEL Classification}

C16; E24; J70

\section{Introduction}

Most of the times, in equal work conditions the salaries of men and women are the same; however, the inertia of tradition and the degree of difficulty concerning the physical or intellectual load required in performing certain jobs lead in fact to discrepancies between the earnings of women and men, on the level of all the EU member states as well as by economical activities.

\section{Methodology}

In assessing the gender pay gap, we used the unadjusted Gender Pay Gap (GPG) indicator. According to the EUROSTAT methodology, the GPG represents the difference between average gross hourly earnings of male paid employees and of female paid employees as a percentage of average gross hourly earnings of male paid employees. The data are broken down by economic activity classification NACE Rev. 2 from reference year 2008; that is the reason why the analysis of activities for the gender gaps was performed starting in 2008. The GPG is calculated at Member States and EU level, by aggregation to the total level of NACE Rev. 2. (except for public administration, defence, compulsory social security) using the arithmetic mean (EUROSTAT). We must mention the fact that for the period of time subjected to the analysis there is no data available on national level pertaining to the GPG values for Greece, and consequently this country was excluded from this study; in the case of Ireland, data is missing for the year 2011, and for Italy and Latvia the data are not broken down by activities for 2008 (in order to ensure the continuity of this analysis, 
instead of the missing data we took into consideration the data existing for 2010), while for Austria the distribution per activities NACE Rev. 2 is available only for 2010 .

\section{Gender pay gap in the EU Member States}

In 2011, on the level of the European Union (UE-27) men had gross hourly earnings $16,2 \%$ higher than women, decreasing by 1,5 percentage points compared to 2006 when there was a gap of $17,7 \%$. According to Figure 1, we can notice that this decreasing trend existing on the level of the European Union pertaining to gender pay gap between 2006-2011 can be seen in most of the states except for Malta, where the GPG increases by 7,7 percentage points - the highest increase registered on EU-27 level -, Romania, Portugal, Hungary (in these countries, the increase is around 4 percentage points) and in Italy, Belgium, Bulgaria, where there is an increase below 1,5 percentage points. The most accentuated decrease of the gender pay gap on EU-27 level was registered in Slovenia, Netherlands, Cyprus, Slovakia and Lithuania (a decrease of over 5 percentage points), while the lowest values, under 1 percentage point, were recorded in France, Sweden and Germany. On territorial profile, on the level of the EU member states there are significant gender pay gaps is 2011 existing gaps of over 22,0\%, much above the EU average, in countries such as Germany, Austria and Estonia, as well as very slight gaps, under 6,0\% in Slovenia, Poland and Italy. On this ranking list, Romania is on the 7 th place out of 26 , with a gender pay gap of $12,1 \%$, value situated below the EU-27 average, Romania being among the countries in which there are no significant gender pay gaps.

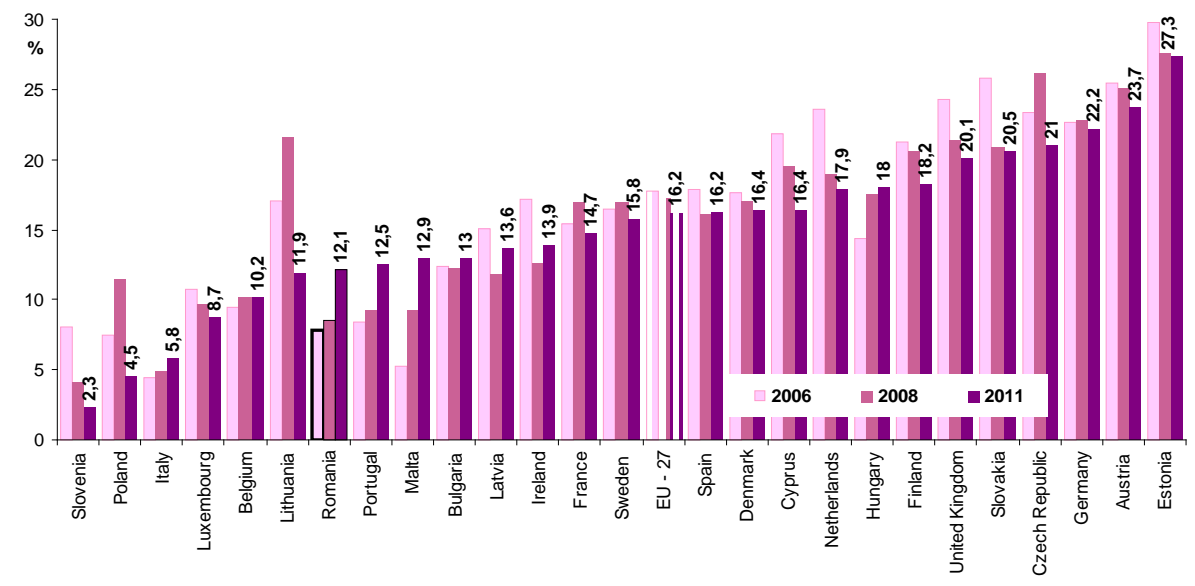

Figure 1 Gender pay gap in the European Union member states (EU-27) in 2006, 2008 and 2011

Source: processing of the data collected from EUROSTAT

Analyzing figure 2 and comparing the histograms concerning the gender pay gap in 2006 and 2011 on territorial profile, we can notice that on the level of the EU member states there is an increasing trend in the degree of sequence symmetry, respectively the migration of the pay gap towards the average values. In other words, the states which at the beginning of this period had low GPG values now have higher values of this indicator and the other way around, in the countries in which the pay gaps were great, there was a decrease during the last 5 years. As to the evolution of Romania, we can state that our country is one of the countries which migrated towards a higher 
interval (while in 2006 Romania was among the 6 countries situated between 5,010,0 , in 2011 our country is listed in the following group, 10,0-15,0, the group with the highest frequency). We can also notice in the boxplots included in fig.2 that the absolute amplitude of the sequence decreases, which means that the differences on territorial profile between the member states are lower and lower, leading to a certain convergence, and that Slovenia does not conform to the other states, having a very low gender pay gap.
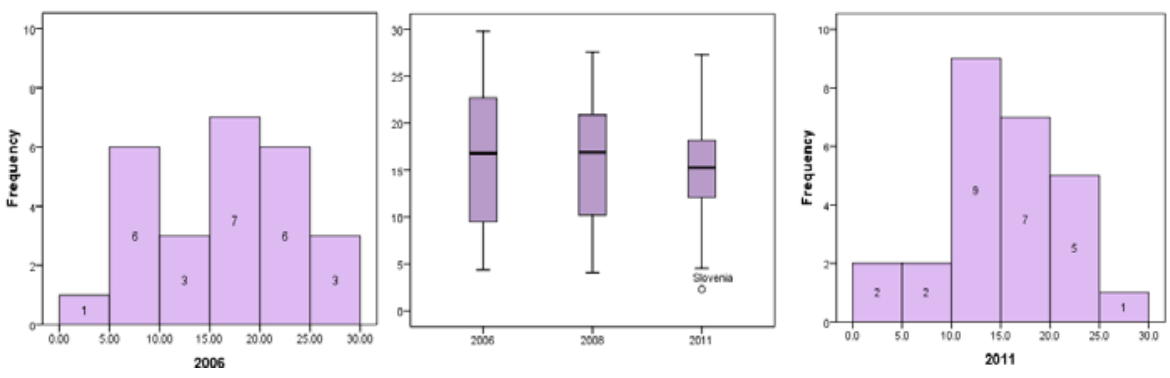

Figure 2 The histogram and the boxplot for Gender pay gap in the member states UE-27 in 2006, 2008 and 2011

Source: processing of the data collected from EUROSTAT

\section{Gender pay gap by Economic Activity in EU Member States}

The evolution of the GPG by economic activity in the EU member states (Fig.3) shows that during the last 3 years there were great gender pay gaps in different activities of the national economy. Thus, as we can see in fig. 3 and 4, while in 2008 in 6 (Slovenia, Portugal, Ireland, Hungary, Bulgaria and Italy) out of the 7 states in which the construction activity offered women higher earnings than men (up to $24,1 \%$ ) this activity was an outliner of the GPG distribution by activities (fig.4), in 2011 only 2 out of the 6 countries listed above (Slovenia and Portugal) maintained a high pay gap, marking a discrepancy compared to the other activities, while in France and Romania the gender pay gap in constructions increased even more compared to the other economic sections. Other activities in which women earned more than men (up to 27,5\% in 2011) were Mining and quarrying (-18,2\% in Hungary in 2011); Water supply; sewerage, waste management and remediation activities $(-12,2 \%$ in France in 2011) and Administrative and support service activities. In Romania, although the GPG in constructions increased from $-10,9 \%$ in 2008 to $-17,1 \%$ in 2011 , this activity is at present the second outliner of the Romanian economy, since there was a higher pay gap in another economic activity: administrative and support service activities - the women who work in this field earned $27,5 \%$ more than the men. We can also notice the fact that these 2 economic activities are the only ones in which women have earned more than men. 


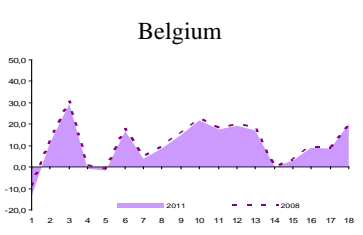

Denmark

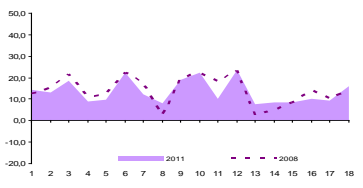

Ireland

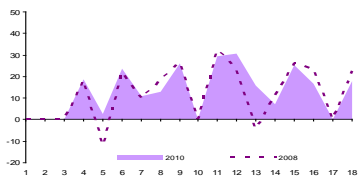

Italy

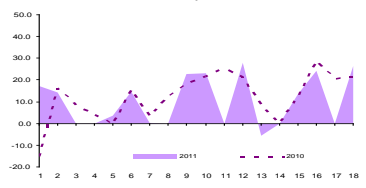

Lithuania

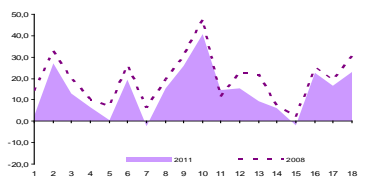

Malta

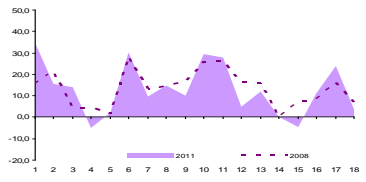

Poland

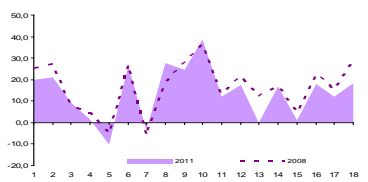

Slovenia

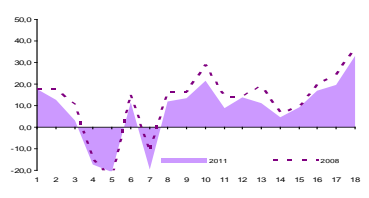

Sweden

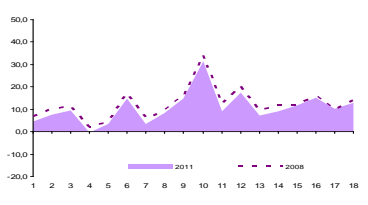

Bulgaria

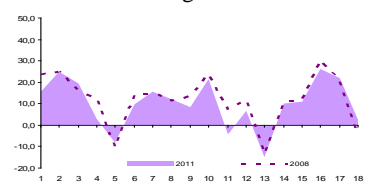

Germany

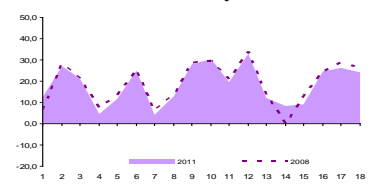

Spain

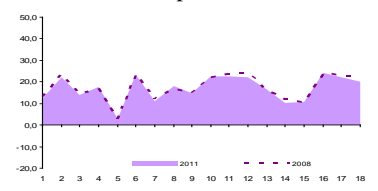

Cyprus

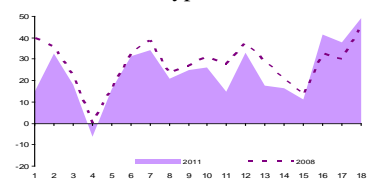

Luxembourg

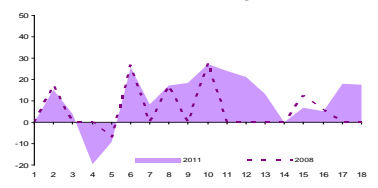

Netherlands

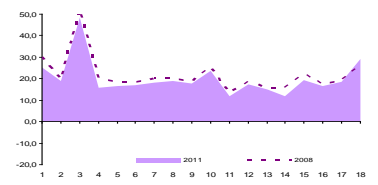

Portugal

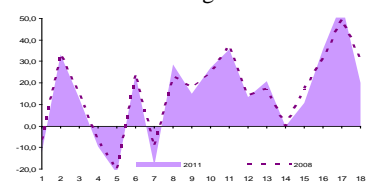

Slovakia

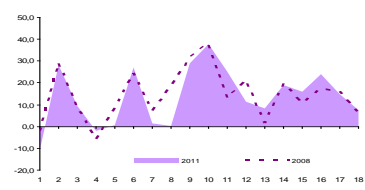

United Kingdom

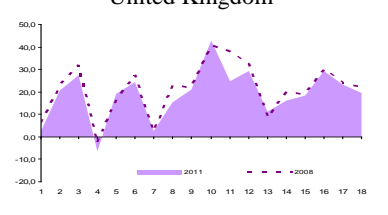

Czech Republic

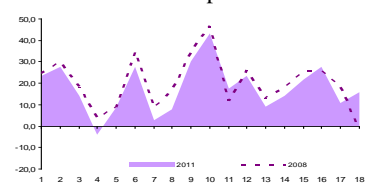

Estonia

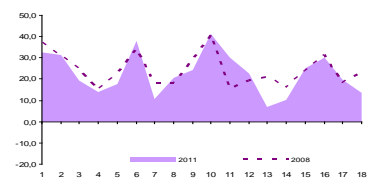

France

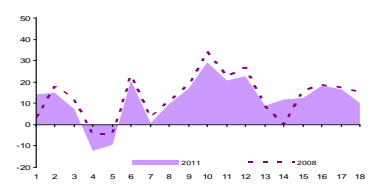

Latvia

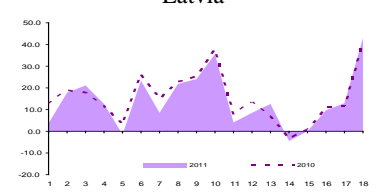

Hungary

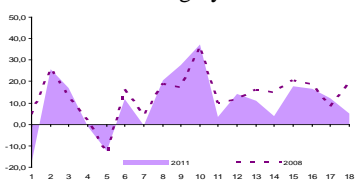

Austria

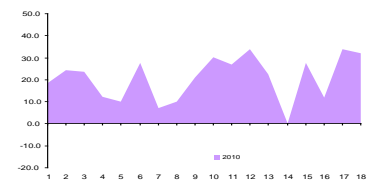

Romania

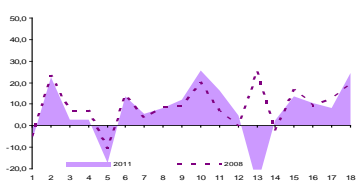

Finland

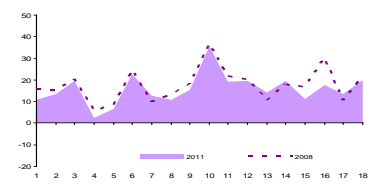

Legend:

$\begin{array}{llrl}1 & \text { Mining } & 10 & \text { Financial activities } \\ 2 & \text { Manufacturing } & 11 & \text { Real estate activities } \\ 3 & \text { Electricity, gas } & 12 & \text { Professional activities } \\ 4 & \text { Water supply } & 13 & \text { Administrative activ } \\ 5 & \text { Construction } & 14 & \text { Public administration } \\ 6 & \text { Retail trade } & 15 & \text { Education } \\ 7 & \text { Transportation } & 16 & \text { Human health } \\ 8 & \text { Accommodation } & 17 & \text { Arts, entertainment } \\ 9 & \text { Communication } & 18 & \text { Other service activ. }\end{array}$

Figure 3 Evolution of the GPG by economic activities for the UE-27

Source: processing of the data collected from EUROSTAT 
As to the positive values of the GPG, the situation in which men earn more than women, the highest values among the EU member states are recorded mainly in financial and insurance activities. While in 2008, in 11 out of the 26 countries subjected to this analysis, this activity had the greatest pay gaps, and in 3 of them (Hungary, Sweden and France) this field was even an outliner, in 2011 Romania was added to the 11 countries; however, the great pay gaps which are in contrast with the other activities of the national economy are recorded this time in the United Kingdom, Finland and Sweden (fig.4). Other activities in which men earned much more than women (up to 57,0\% in 2011) were Arts, entertainment and recreation (in Portugal in 2011); Electricity, gas, steam and air conditioning supply (in the Netherlands) and Other service activities. In Romania the trend existing on the level of the other EU member states was maintained, even though in 2008 the highest value of the GPG was registered in administrative and support service activities (25,8\%), in 2011, since in the case of this activity there was a significant decrease, the men working in financial and insurance activities earned 25,8\% more than the women.
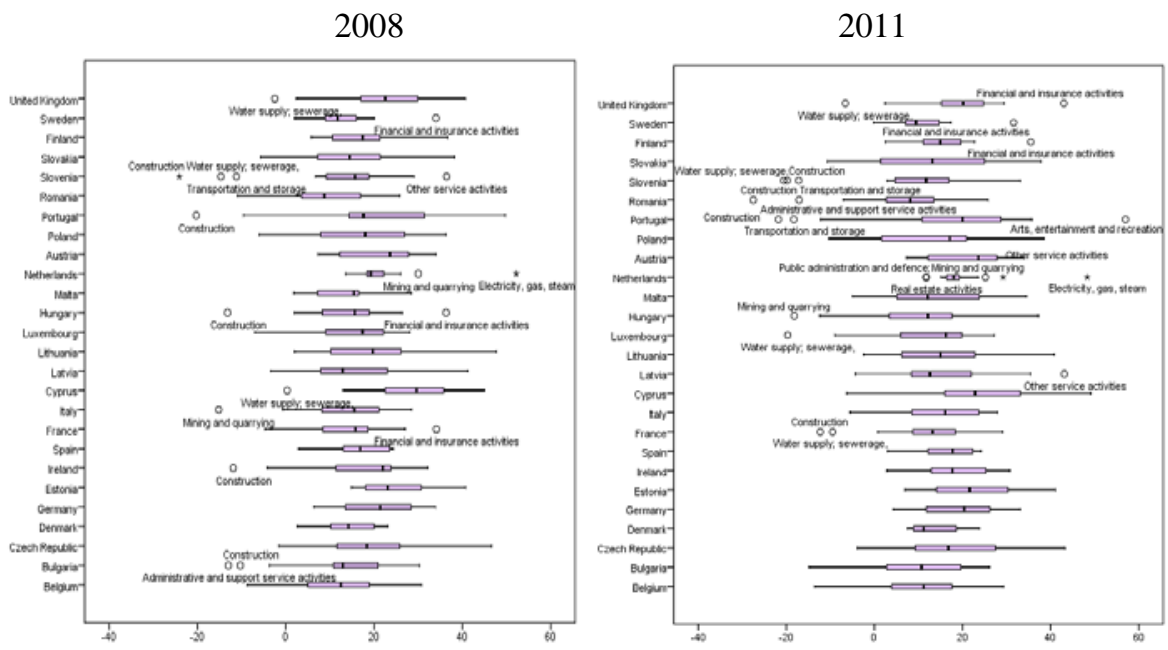

Figure 4 Boxplot for GPG on each of the UE-27 member states according to the distribution per activities

Source: processing of the data collected from EUROSTAT

Speaking of the GPG discrepancies among the activities of the national economy on the level of the EU member states, we can notice the fact that the Netherlands stands out due to a high homogeneity of the sequence, which means that the gender pay gaps among the economic activities are very low (up to 17,5 percentage points in 2011, if we exclude the highest value which shows discrepancy with the sequence - $48,3 \%$ in Electricity, gas, steam and air conditioning supply). The same high homogeneity of the sequence can be seen in the countries in which there are the lowest discrepancies among the economical activities (determined by the absolute difference between the highest and the lowest value of the GPG) in 2008 as well as in 2011: Denmark (up to 20,5 and 16,3 percentage points respectively) and Spain (with 21,5 and 21,3 percentage points respectively), while in the countries in which the absolute amplitude of the sequence has high values we can notice a high heterogeneity of the sequence, with great differences from one activity to another: Portugal (up to 70,0 and 
78,8 percentage points respectively), Slovenia (up to 60,5 and 53,7 percentage points respectively) and Hungary (up to 49,5 and 55,4 percentage points respectively).

\section{Conclusion}

The principle of equal payment for men and women for an equivalent amount of work is written in the EU treaties; however, the reality is that there are gender pay gaps on the level of the EU member states and among them (Arulampalam $\mathrm{W}$ et al, 2007). Even though in all the countries subjected to this analysis men earned more than women, this situation improved during the last 6 years, a slight convergence of the pay gap occurring among the EU member states. One of the causes for the pay gap is the segregation of the labour market, since women and men still tend to work mainly in certain economic fields, so that most activities in which women earned more than men (e.g.: construction, mining and quarrying, water supply; sewerage, waste management and remediation activities) are in fact fields in which men employees are dominant, women employees having very low total percentage and having, in general, administrative duties in companies, while in financial and insurance activities, where the percentage of women employees is quite high, the greatest pay gaps were registered in favour of men. On territorial profile, the gender gaps also reflect other types of inequities on the labour market specific to each particular economy (Blau $\mathrm{F}$ \& Kahn L, 2003), so that in countries such as the Netherlands, Denmark and Spain, where there is a certain social and economical stability, there are low discrepancies among the economic activities, while in Slovenia, Hungary as well as in Romania (former communist states) the adaptation of the economy to the EU space still causes great pay gaps among different activities (Newell A \& Reilly B, 2001).

\section{References}

Arulampalam, W, Booth, A, Bryan, M (2007), Is There a Glass Ceiling over Europe? Exploring the Gender Pay Gap across the Wage Distribution, Industrial and Labor Relations Review, Cornell University, 60(2), 163-186.

Blau, F, Kahn, L (2003), Understanding International Differences in the Gender Pay Gap, Journal of Labor Economics, University of Chicago Press, 21(1), 106144.

Newell, A, Reilly, B (2001), The gender pay gap in the transition from communism: some empirical evidence, Economic Systems, Elsevier, vol. 25(4), pp 287-304

Harja, E, Stângaciu, OA (2009), Analiza datelor statistice folosind SPSS, Bacău, Editura Alma Mater.

EUROSTAT - Gender Pay Gap Statistics available on http://epp.eurostat.ec.europa.eu/statistics_explained/index.php/Gender_pay_ga p_statistics . 